\title{
Self-reported endocrine late effects in adults treated for brain tumours, Hodgkin and non-Hodgkin lymphoma: a registry based study in Northern Germany
}

\author{
Judith Gebauer*, Eva-Maria Fick, ${ }^{1, *}$, Annika Waldmann ${ }^{1}$, Thorsten Langer ${ }^{2}$, \\ Ilonka Kreitschmann-Andermahr ${ }^{3}$, Hendrik Lehnert, Alexander Katalinic ${ }^{4}$ \\ and Georg Brabant
}

\begin{abstract}
Experimental and Clinical Endocrinology, Department of Internal Medicine I, University Hospital of Schleswig-Holstein, Campus Luebeck, Ratzeburger Allee 160, 23538 Luebeck, Germany, 'Institute of Social Medicine and Epidemiology, University Luebeck, Ratzeburger Allee 160, 23538 Luebeck, Germany, ${ }^{2}$ Department of Pediatric Hematology and Oncology, University Hospital of Schleswig-Holstein, Campus Luebeck, Ratzeburger Allee 160, 23538 Luebeck, Germany, ${ }^{3}$ Department of Neurosurgery, University Hospital of Essen, Hufelandstr. 55, 45147 Essen, Germany and ${ }^{4}$ Institute of Cancer Epidemiology e.V., University Luebeck, Ratzeburger Allee 160, 23538 Luebeck, Germany

Correspondence should be addressed to G Brabant Email georg.brabant@uksh.de

\begin{abstract}
Objective: Due to the increasing success and survival rates in the primary treatment of malignancies derived from the CNS as well as the hematopoietic system, endocrine late effects of cancer and its therapy are of growing importance. Despite evaluation of these late effects in patients treated for cancer in childhood, the impact on adults remains largely unclear. Methods: 1035 adult patients primarily diagnosed with a CNS malignancy, a Hodgkin (HL) or non-Hodgkin lymphoma (NHL) between 1998 and 2008 were recruited via the regional epidemiological cancer registry covering $\sim 2.8$ million inhabitants in the federal state of Schleswig-Holstein, Northern Germany. The prevalence of endocrine disorders and current psychosocial impairment was assessed employing several questionnaires (SF-36v1, WHO-5).

Results: Fully completed questionnaires of 558 patients were available for subsequent analysis showing markedly reduced overall performance and psychological status when compared to German reference data. Thyroid disorders were reported in $16.3 \%$ of patients with $10.4 \%$ suffering from hypo- and $5.9 \%$ from hyperthyroidism. Overall, $17.6 \%$ stated to be affected by diabetes mellitus with an increased rate of $21.1 \%$ among NHL patients and $11.5 \%$ of participants were affected by osteoporosis.

Conclusion: Compared to German population based studies on the prevalence of diabetes mellitus, osteoporosis and thyroid disorders the frequency of all these endocrine problems was significantly increased in CNS, HL, and NHL cancer survivors. These data confirm that not only children and adolescents but also adult cancer patients are at risk for therapy associated endocrine late effects.

\section{Introduction}

With increasingly successful therapeutic strategies for a wide spectrum of malignancies a continuously growing number of long-term cancer survivors have been (c) 2015 European Society of Endocrinology Printed in Great Britain recognized to suffer from late effects of either the cancer itself or treatment sequelae $(1,2,3)$. Large register based studies from the UK and USA which focussed on the 
long-term effects in children suggested that a large number of these cancer survivors are particularly affected by late effects on the endocrine system. From these childhood data, it can be expected that overall between two and three million patients in Germany suffer from at least one chronic condition following cancer therapy $(4,5,6)$. However, there are only a few systematic studies on late effects in adult cancer patients so far although the latter constitute the vast majority of long-term cancer survivors $(7,8,9,10)$.

Follow-up by oncologists is conventionally performed within a time frame of 5 years after the initial diagnosis of a malignant disease in accordance with tumour-specific guidelines. A patient who remains cancer-free thereafter is considered to be cured and the frequency of routine work-up is drastically reduced $(11,12)$. Subsequent examinations aim at detecting signs of relapse or progression of the malignant disorder but not on the identification of therapy-related effects. International studies including a systematic clinical follow-up on extended cohorts revealed that the risk of relapse decreases with an increasing time interval to the initial diagnosis; in contrast, the incidence particularly of endocrine late effects remains significantly elevated for many years even in the absence of any signs of relapse from the initial malignant disease. These data are almost exclusively derived from paediatric cancer survivors with a prevalence of at least one chronic disease in up to $70 \%$ of cases 30 years after initial diagnosis and about $50 \%$ related to an endocrine disorder $(13,14)$. These effects are frequently associated with unspecific symptoms such as fatigue and impaired capability of physical performance. Their clinical significance as well as the need for a specific diagnostic investigation is comprehensively outlined in several guidelines including the recently published German guideline on 'Endocrine aftercare following oncological diseases in childhood and adolescence' (http://www.awmf.org/leitlinien/ detail/1l/025-030.html) as well as the Scottish guideline on 'Long term follow up of survivors of childhood cancer' (http://www.sign.ac.uk/pdf/sign132.pdf). Currently, however, it is still unclear to what extent these observations can be adopted for the oncological follow-up of late effects after treatment for a malignant disorder in patients who were adults at initial diagnosis. Currently, no systematic data on the prevalence of endocrine sequelae of cancer therapy in adults are available.

As data from children and adolescents suggested that the highest frequency of endocrine late effects are observed in patients with Hodgkin (HL) or non-Hodgkin lymphoma (NHL) and CNS tumours (CNS-T) we restricted our analysis to these patients $(15,16,17,18,19)$.
In the present study we thus assessed the prevalence and distribution of endocrine late effects in adult longterm cancer survivors. This analysis should explore the frequency of late effects in this cohort which will help to generate programs for a structured follow-up program aimed at the early detection of late effects in this continuously growing population.

\section{Subjects and methods}

Potential study participants for our study on endocrine late effects in cancer survivors were identified by the dataset of the epidemiologic cancer registry of the federal state of Schleswig-Holstein, Germany. We restricted our analysis to patients with CNS-T (CNS-T, defined as ICD-10 C71), HL (HL defined as ICD-10 C81) or NHL (NHL defined as ICD-10 C82, C83, C84 or C85) diagnosed and initially treated between 1998 and 2008. All patients consented to be contacted for research purposes at the time of notification to the registry.

We contacted 1033 participants 5-15 years after diagnosis of CNS-T $(8.8 \%, n=91)$, HL $(22.6 \%, n=233)$ or NHL $(68.6 \%, n=709$; of these 222 patients with C82, 385 with C83, 34 with C84 and 68 with C85) (Supplementary Table S1, see section on supplementary data given at the end of this article) and asked to complete a set of questionnaires including items about demographic data, selected symptoms of endocrine diseases as well as self-reported physical and cognitive impairment. The paper-based questionnaire contained the following validated and reliable questionnaires: the Medical Outcomes Study 36-item Short Form Health Survey (SF-36v1) $(20,21)$ and the WHO-5 questionnaire about well-being (22). The remaining questions were tested with ten persons for their comprehensibility.

The health-related quality of life (HRQOL) was determined by using the SF-36v1 $(20,21)$ and depressive symptoms by using the WHO-5 questionnaire about wellbeing (22). The scales of the SF-36v1 are scored from 0 to 100, with higher scores representing a better HRQOL. Clinicopathological data were provided by the registry.

\section{Statistical analyses}

Qualitative data was described with relative and absolute frequencies and quantitative data with arithmetic mean and S.D.

According to the manual raw data from the SF-36v1 was summarized into the physical (PCS) and the mental component scale (MCS). Those scores were transformed into norm-based scores, using normative data for the 
German population $(20,21)$. The WHO-5 (including five questions) was analyzed using the sum score, with a maximum of five points per question (22). A score below 13 indicates poor wellbeing and is an indication for testing for depression under ICD-10 (http://www.gp-training.net/ protocol/psychiatry/who/whodep.htm). A sum score of 19-25 represents very good well-being while a score of less than seven points indicates a clinically relevant depression. Correlation between the categorized WHO-5 sum scores and the PCS and MCS was tested with Spearman correlation.

For comparing the prevalence of selected endocrine diseases the age-adjusted prevalence rates of the general population were calculated on the basis of current epidemiological studies from Germany $(23,24,25,26)$.

Because of the slight difference between the entity groups prevalences are reported separately by sex. Data were analysed using SPSS version 20.

\section{Ethical approval}

The study protocol was approved by the ethical review board of the University of Luebeck.

\section{Results}

\section{Study participants}

Of the 1033 patients contacted, 557 (response rate 53.9\%) responded with completed questionnaire and informed consent to participate in the study; $12(1.2 \%)$ completed questionnaires were sent back but no informed consent was given. Furthermore, 62 (6.0\%) persons actively refused participation, meaning that these patients responded to the questionnaire but stated at the beginning of the survey that they did not want to participate in the study. 237 (22.9\%) persons did not respond and 94 (9.1\%) persons moved to an unknown address. 72 (6.9\%) persons were already deceased.

There were no notable differences between responding and eligible non-responding persons (excluding deceased persons and those who moved to unknown address). The non-responders received radiotherapy (52.4\% vs $60.8 \%)$, immunotherapy (9.0\% vs $14.2 \%$ ) and bone marrow transplantation (1.3\% vs $3.9 \%)$ less often. Men responded more often $(51.4 \%$ vs $56.3 \%)$ as compared to women (48.6\% vs $43.7 \%)$. All these trends did not reach statistical significance. Furthermore, age at diagnosis $(53.3 \pm 16.5$ years vs $52.7 \pm 14$.6 years) and mean follow up time ( $8.9 \pm 2.9$ years vs $9.2 \pm 3.0$ years) did not differ between the two groups.
The overall population consisted of 313 (56.2\%) men and 244 women, of whom 42 patients had a CNS-T (7.5\%), 117 patients were diagnosed with HL (21.0\%) and 398 patients with NHL (71.5\%; of these 139 patients with C82, 218 with C83, 5 with C84 and 36 with C85). The mean age at diagnosis was $52.7 \pm 14.6$ years. The NHL-participants (mean age $=56.7 \pm 12.5$ years) were about $10-15$ years older at diagnosis than participants with CNS-T or HL. The time since diagnosis was on average $9.6 \pm 3.0$ years. The mean BMI was $27.2 \pm 5.79 \mathrm{~kg} / \mathrm{m}^{2}$. Altogether $48.1 \%(n=268)$ of participants underwent surgery, $76.1 \%(n=424)$ received chemotherapy and $60.9 \%(n=339)$ received radiotherapy (Table 1$) .14 .2 \%(n=79)$ of participants reported a recurrence and only $1.1 \%(n=6)$ metastases.

\section{Secondary diseases and medication}

On average about $17.2 \%$ of participants were treated with any kind of thyroid medication $(n=96)$ (Table 2$)$. The most frequently reported cause for hormone replacement was hypothyroidism (in total: $10.4 \%, n=58$; CNS-T 9.5\%, $n=4$; HL $18.3 \%, n=22$; NHL $8.0 \% ; n=32$ ) (Fig. 1). Hyperthyroidism was reported by $5.9 \%$ of all study participants $(n=33$; CNS-T $11.9 \%, n=5$; HL $4.3 \%, n=5$; NHL $5.8 \%, n=23)$, and 9.2\% reported thyroid nodules $(n=51$; CNS-T 9.5\%; $n=4$; HL $6.8 \% ; n=8$; NHL $9.8 \% ; n=39)$. Goiter was reported by $3.9 \%$ of participants $(n=22$; CNS-T 9.3\%, $n=4$; HL 3.4\%, $n=4$; NHL $3.5 \%, n=14$ ).

Overt diabetes mellitus was reported by $17.6 \%(n=98)$ of participants. This was particularly frequent in the subgroup of patients with NHL (CNS-T 7.1\%, $n=3$; HL 9.4\%, $n=11$; NHL 21.1\%, $n=84$; Fig. 1). Fitting to these data $13.5 \%$ of participants reported to receive antidiabetic medication (in total $n=75$; CNS-T $2.4 \%, n=1$; HL $6.8 \%$, $n=8$; NHL $16.6 \%, n=66$; Table 2).

The self-reported prevalence of hyperlipidemia was $28.9 \%(n=161$; CNS-T 23.3\%, $n=10$; HL $23.3 \%, n=27$; NHL $32.4 \%, n=124)$. Osteoporosis was reported by $11.5 \%$ ( $n=64$ ) of participants (NHL $13.3 \%, n=53$; HL $5.1 \%, n=6$; CNS-T $11.6 \%, n=5)$ and $50.3 \%(n=280)$ reported symptoms indicative for muscle- and joint-disorders.

Currently, ongoing replacement therapy with recombinant growth hormone $(\mathrm{GH})$ was reported by $0.4 \%(n=2$; NHL $0.3 \%, n=1$; HL $0.9 \%, n=1)$, while $1.1 \%(n=6)$ reported previous treatment with $\mathrm{GH}$ at some point since diagnosis (NHL $0.8 \%, n=3$; HL 2.5\%, $n=3$ ).

Finally, erectile dysfunction was reported by $41.1 \%$ of male participants ( $n=128$; CNS-T $35.0 \%, n=7$; HL $28.2 \%$, $n=20$; NHL $46.3 \%, n=101$; Fig. 2). Of the participating women, $29 \%$ reported that menopause occurred abruptly 
Table 1 Characteristics of the study participants (absolute and (relative)) frequencies.

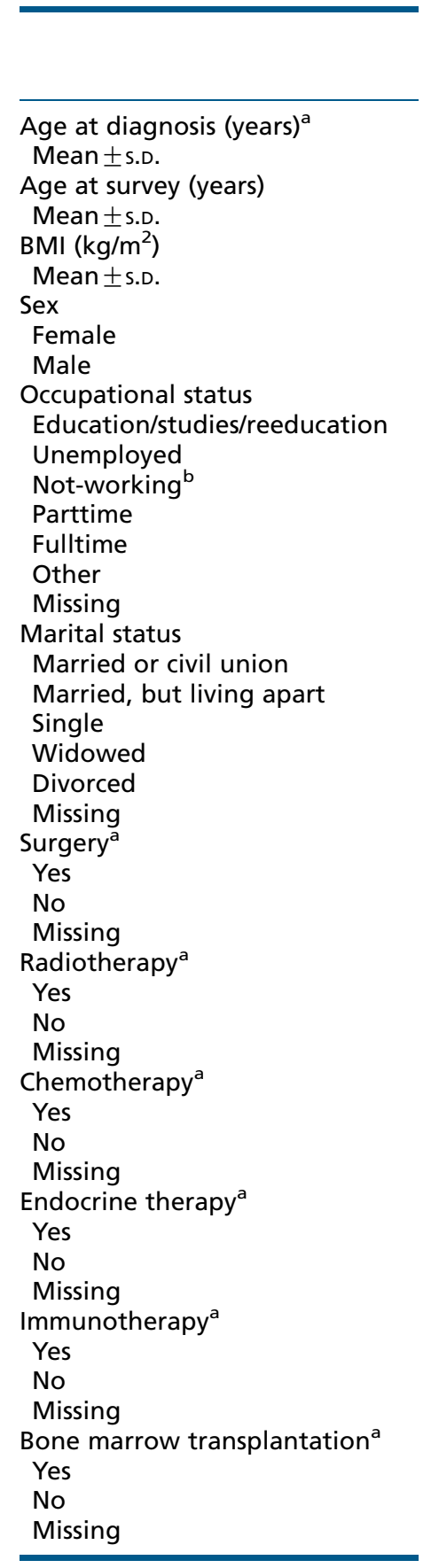

\begin{tabular}{c} 
All \\
\hline$n=557$
\end{tabular}

\begin{tabular}{c} 
NHL \\
\hline$n=398$
\end{tabular}

$52.7 \pm 14.6$

$62.3 \pm 14.5$

$27.2 \pm 5.2$

244 (43.8)

313 (56.2)

$7(1.3)$
$4(0.7)$
$358(64.3)$
$34(6.1)$
$117(21.0)$
$19(3.4)$
$18(3.2)$

358 (64.3)

$10(1.8)$

61 (11.0)

58 (10.4)

$51(9.2)$

19 (3.3)

268 (48.1)

201 (36.1)

88 (15.8)

339 (60.9)

127 (22.8)

91 (16.3)

424 (76.1)

95 (17.1)

$38(6.8)$

$$
7 \text { (1.3) }
$$

332 (59.6)

218 (39.1)

79 (14.2)

244 (43.8)

234 (42.0)

22 (3.9)

276 (49.6)

259 (46.5)

$56.7 \pm 12.5$

$66.2 \pm 12.4$

$27.2 \pm 5.1$

176 (44.2)

$222(55.8)$

$4(1.0)$
$2(0.5)$
$284(71.4)$
$22(5.5)$
$57(14.3)$
$16(4.0)$
$13(3.3)$
$268(67.3)$
$6(1.5)$
$27(6.8)$
$50(12.6)$
$34(8.5)$
$13(3.3)$

171 (43.0)

161 (40.5)

66 (16.6)

209 (52.5)

$112(28.1)$

77 (19.3)

292 (73.4)

77 (19.3)

29 (7.3)

6 (1.5)

236 (59.3)

$156(39.2)$

77 (19.3)

163 (41.0)

158 (39.7)

22 (5.5)

194 (48.7)

$182(45.7)$

\begin{tabular}{c}
$\mathbf{H L}$ \\
\hline$n=117$
\end{tabular}

\begin{tabular}{c} 
CNS-T \\
\hline$n=42$ \\
\hline
\end{tabular}

$42.4 \pm 15.5$

$43.7 \pm 13.0$

$52.4+15.5$

$53.1 \pm 12.8$

$27.3 \pm 5.7$

$26.6 \pm 4.7$

46 (39.3)

71 (60.7)

22 (52.4)

20 (47.6)

3 (2.6)

$0(0.0)$

$1(0.9)$

44 (37.6)

$12(10.3)$

51 (43.6)

3 (2.6)

3 (2.6)

68 (58.1)

$0(0.0)$

26 (22.2)

$7(6.0)$

$11(9.4)$

5 (4.3)

57 (48.7)

39 (33.3)

21 (17.9)

91 (77.8)

14 (12.0)

$12(10.3)$

1 (2.4)

30 (71.4)

$0(0.0)$

9 (21.4)

$0(0.0)$

$2(4.8)$
111 (94.9)

3 (2.6)

3 (2.6)

$0(0.0)$

65 (55.6)

52 (44.4)

2 (1.7)

50 (42.7)

65 (55.6)

$0(0.0)$

$51(43.6)$

66 (56.4)
$22(52.4)$

4 (9.5)

8 (19.0)

1 (2.4)

$6(14.3)$

1 (2.4)

40 (95.2)

1 (2.4)

1 (2.4)

39 (92.9)

1 (2.4)

2 (4.8)

$21(50.0)$

15 (35.7)

$6(14.3)$

1 (2.4)

31 (73.8)

10 (23.8)

$0(0.0)$

31 (73.8)

$0(0.0)$

31 (73.8)

$11(26.2)$
$11(26.2)$

${ }^{a}$ Register data.

${ }^{b}$ Retirement, disability annuity, housework, illness/unable to work.

after their cancer treatment ( $n=70$; CNS-T 12.9\%, $n=9$; HL 20\%, $n=14$; NHL $67.1 \%, n=47$ ). The mean age of these women was $45.5 \pm 8.7$ years (CNS-T $41.7 \pm 8.5$ years, HL $41.1 \pm 7.9$ years, NHL $47.5 \pm 8.4$ years). Altogether $20 \%$ $(n=14)$ of the affected women were under or at the age of 40 years.

\section{HRQOL and well-being}

Altogether $54.6 \%(n=304)$ of the participants reported increased lack of energy, tiredness and inefficiency. These symptoms occurred more frequently in the CNS-T group than in all other groups (CNS-T 73.8\%, $n=31$; HL 44.4\%, $n=52$; NHL $55.5 \%, n=221$ ). 
Table 2 Reports of current medication of the study participants (absolute and (relative)) frequencies.

\begin{tabular}{|c|c|c|c|c|}
\hline & All & NHL & HL & CNS-T \\
\hline & $n=557$ & $n=398$ & $n=117$ & $n=42$ \\
\hline \multicolumn{5}{|l|}{ Antihypertensive drugs } \\
\hline Yes & $254(45.6)$ & $200(50.3)$ & $43(36.8)$ & $11(26.2)$ \\
\hline No & 300 (53.9) & $196(49.2)$ & $74(63.2)$ & $30(71.4)$ \\
\hline Missing & $3(0.5)$ & $2(0.8)$ & 0 & $1(2.3)$ \\
\hline \multicolumn{5}{|l|}{ Antidiabetics } \\
\hline Yes & 75 (13.5) & $66(16.6)$ & $8(6.8)$ & $1(2.4)$ \\
\hline No & $480(86.2)$ & 330 (82.9) & $109(93.2)$ & $41(97.6)$ \\
\hline Missing & $2(0.4)$ & $2(0.5)$ & 0 & 0 \\
\hline \multicolumn{5}{|l|}{ Thyroid medications } \\
\hline Yes & $96(17.2)$ & $56(14.1)$ & $33(28.2)$ & 7 (16.7) \\
\hline No & $460(82.6)$ & 341 (85.7) & $84(71.8)$ & $35(83.3)$ \\
\hline Missing & $1(0.2)$ & $1(0.3)$ & 0 & 0 \\
\hline \multicolumn{5}{|l|}{ Antidepressants } \\
\hline Yes & $60(10.8)$ & $46(11.6)$ & $8(6.8)$ & $6(14.3)$ \\
\hline No & $495(88.9)$ & $350(87.9)$ & $109(93.2)$ & $36(85.7)$ \\
\hline Missing & $2(0.4)$ & $2(0.5)$ & 0 & 0 \\
\hline Male sexual hormones ${ }^{a}$ & $n=313$ & $n=222$ & $n=71$ & $n=21$ \\
\hline Yes & $3(1.0)$ & $2(0.9)$ & $1(1.4)$ & 0 \\
\hline No & $306(97.8)$ & $216(97.3)$ & $70(98.6)$ & $20(100.0)$ \\
\hline Missing & $4(1.3)$ & $4(1.8)$ & 0 & 0 \\
\hline \multicolumn{5}{|l|}{ Growth hormones } \\
\hline Yes & $2(0.4)$ & $1(0.3)$ & $1(0.9)$ & $0(0.0)$ \\
\hline No & $551(98.9)$ & $393(98.7)$ & $116(99.1)$ & $42(100.0)$ \\
\hline Missing & $4(0.7)$ & $4(1.0)$ & 0 & 0 \\
\hline
\end{tabular}

According to the results of the WHO-5 questionnaire clinically relevant depression was observed in $11.7 \%$ $(n=65)$ of participants (CNS-T 28.6\%, $n=12$; HL $11.1 \%$, $n=13$; NHL $10.1 \%, n=40$; Fig. 3 ). In addition, the results of the SF-36v1 questionnaire showed overall good mental

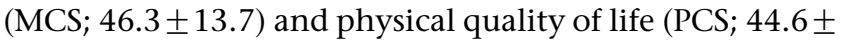
11.6). WHO-5 sum scores correlated highly with PCS (rs $=0.378, P<0.001$ ) and MCS scores (rs $=0.707$, $P<0.001)$. Accordingly, SF-36v1 scores were lowest for those with a clinical relevant depression according to the WHO-5 criteria (WHO-5 score <7; PCS 24.9 \pm 12.5 , MCS $36.5 \pm 11.0$ ) (Fig. 3).

\section{Contact to physician}

In the last 12 months before the survey, almost all participants $(98.9 \%, n=545)$ had contact to a physician and most frequently to a general practitioner $(87.3 \%$, $n=477$ ). Concerning other medical specialisations, NHL-participants most frequently visited an ophthalmologist $(52.6 \%, n=204)$, HL-participants an oncologist $(38.8 \%, n=45)$ and the CNS-T-participants a neurologist $(68.3 \%, n=28)$.

\section{Discussion}

Late effects of cancer treatment are an increasingly recognized problem. It has been described predominantly in patients suffering from cancer during childhood and adolescence whereas hardly any data are available for the huge majority of patients treated for cancer in adulthood $(7,8,9,10)$. This study is the first population-based survey focussing on self-reported potential endocrine late effects in adult cancer survivors. When comparing results from this registry based study to currently available epidemiological data on the frequency of endocrine disorders in Germany $(23,24,25,26)$, an increased prevalence of these diseases in adult long-term cancer survivors is obvious and similar to that observed in patients diagnosed with cancer during childhood and adolescence $(13,17)$.

To the best of our knowledge this is the first report revealing an enhanced incidence of disorders such as osteoporosis (11.5\% vs $7.6 \%$ in the general population) and diabetes mellitus (17.6\% vs $13.8 \%)$ in a German cohort of adults followed after cancer treatment. We compared our data to recently published, age-adjusted normative data derived from large population based 

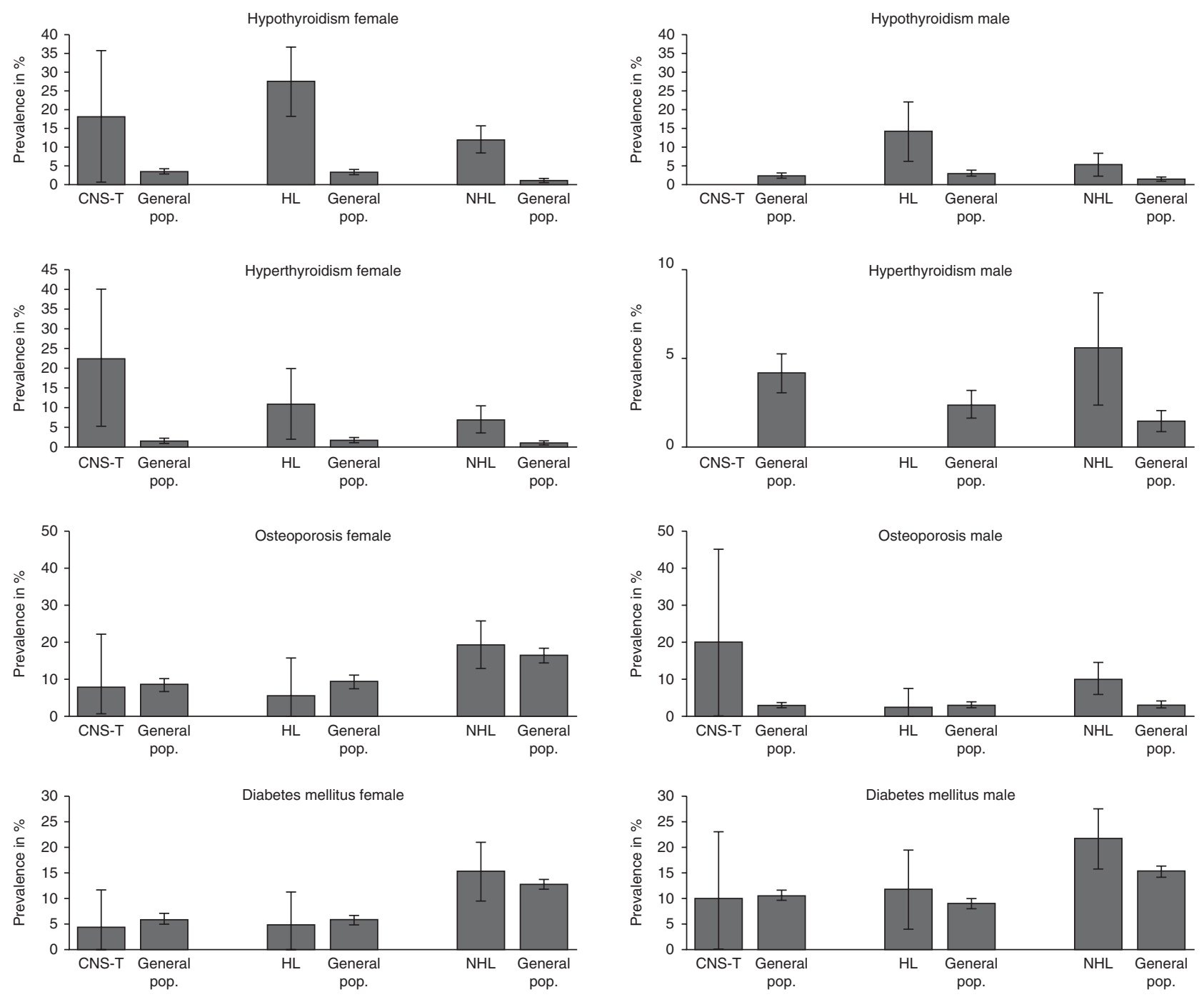

\section{Figure 1}

Prevalence (percent with $95 \% \mathrm{Cl}$ ) of selected diseases in the study population and the general population $(23,24,25)$.

studies from Germany as no data set of an age and sex matched cohort for a case control study was available $(24,25)$ (Fig. 1). These observations fit to previously published studies from UK where the evaluation of a General Practitioner database revealed a comparably increased risk of osteoporosis and diabetes, particularly in patients with non-Hodgkin disease. Interestingly, despite our expectations that children and adolescents would be more prone to develop late effects, especially of the bone, the frequencies of adult late effects observed in this study appear to be largely similar $(5,27,28,29,30$, $31,32,33)$. There are a number of potential underlying mechanisms, which due to the nature of the study must

Inclusion criteria (osteoporosis): patients $\geq 50$ years (male: $n=211$, female $n=159$ ).

remain speculative. They include the frequent therapeutic use of corticosteroids in the context of chemotherapy, a transient or persistent hypogonadism or radiation therapy of the abdomen and/or the skeletal system (34).

Functional deficiencies of the thyroid gland also occur at an elevated frequency $(17.2 \%$ vs $11.6 \%)$ when comparing our data with German age-adjusted population-based studies (26). The incidence of replacement therapy in the context of hypothyroidism was elevated more than twofold (10.4\% vs $4.8 \%)$. Comparably, a substantial impact of long-term cancer survivorship following cancer treatment was identified for the overall less common hyperthyroidism, the causes of which were 


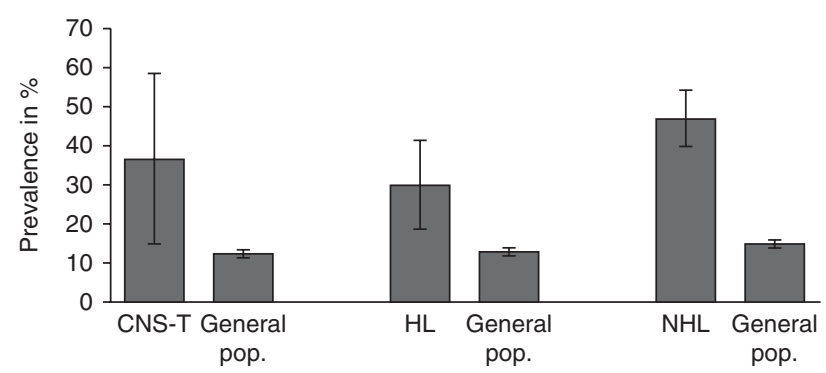

Figure 2

Prevalence (percent with $95 \% \mathrm{Cl}$ ) of erectile dysfunction in the male study population and the general population (39).

not assessable in the current self-disclosure based study (23). Numerous past studies were able to profoundly establish irradiation of the head and neck region as an independent and dose dependent risk factor for the development of a functionally relevant thyroid disorder (35). We could not demonstrate an increased frequency of new benign and/or malignant thyroid nodules in our cohort of cancer survivors. As ultrasound of the thyroid is typically used in the standard evaluation of patients treated with thyroid medication in Germany this finding argues against an important role of cancer treatment in the formation of new thyroid nodules. The results contradict the findings in children and adolescents where the nodular changes due to irradiation are increased $(36,37)$. Potential causes for this apparent discrepancy remain speculative. They include an elevated sensitivity towards irradiation in the thyroid gland at a younger age and changes in the overall dose of irradiation. The latter appears to be relevant as the impact on the risk of developing a thyroid carcinoma is reversed at a cumulative irradiation dose of $>20$ Gy due to the continuous destruction of the organ itself. These data were however not retrieved for this study. Moreover, the length of clinical follow-up needs to be considered in this context as the majority of irradiation induced thyroid malignancies arise $>10$ years after local radiotherapy. It appears possible that the median time of clinical follow-up was too short in our current study and therefore no significantly elevated incidence of secondary malignancies was observed in any location as exemplarily depicted for thyroid neoplasia $(14,38)$.

Almost half of all male participants in our study reported on reduced libido and/or erectile dysfunction. This resembles a significant increase of the specific relative risk when compared to the general population (Fig. 2) (39). These observations are most likely secondary effects caused by a therapy-associated decrease in gonadal functionality $(40,41,42,43)$. As untreated male hypogonadism (frequently observed following cranial irradiation) is a major risk factor for the development of premature osteoporosis, this may be one explanation for the high prevalence of this disorder in male long-term cancer survivors.

As the average age within the study group at diagnosis was 52.7 years, only a minor fraction developed acute or premature ovarian failure as frequently described after childhood cancer treatment (44). Due to this composition of our study group a systematic analysis of potential deficiencies in female sex hormones and their functional implications was not performed. It would however be interesting to assess this topic in further studies.

Numerous studies found a lack in GH (GH-deficiency) to be a dose dependent adverse effect of an irradiation of the neurocranium $(18,19,45,46)$. Surprisingly, only $1.1 \%$ of participants in our current study received a $\mathrm{GH}$ replacement therapy. None of these had been treated for tumours of the CNS, which are frequently treated by local radiation therapy and may subsequently develop GH deficiency. Adult-onset GH-deficiency (e.g. following cancer treatment) may lead to rather unspecific clinical manifestations including chronic fatigue-like symptoms, constipation, dry skin and weight increase. Interestingly, a substantial subset of our patients reported such symptoms with no apparent concurring clinical cause. It is therefore tempting to speculate that the number of diagnosed patients and the real number of long-term cancer survivors suffering from GH-deficiency may substantially differ due to a lack of clinical awareness (47) and that at least a proportion of symptoms categorized as 'chronic fatigue syndrome', may result from undiagnosed secondary endocrine disorders $(48,49)$.

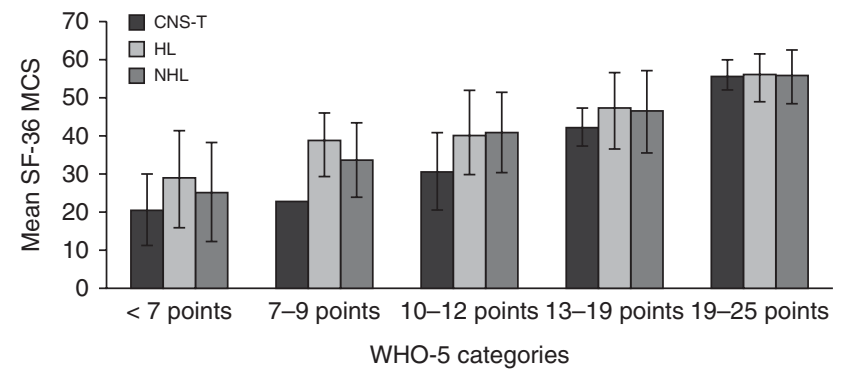

Figure 3

Results for the SF-36 mental component scale (mean with S.D.) separated by WHO- 5 categories ( $<13$ points indicating poor well-being) and tumour entity. 
This may have a major impact on the care of patients as the specific needs of long-term cancer survivors concerning these endocrine problems may not be sufficiently met in the transition from primary oncological care to routine GP follow-up $(15,50,51)$. Moreover, complex endocrinological disorders such as pituitary deficiency require specialized endocrinological evaluation not generally included in the previous mentioned settings which may result in these diseases remaining underdiagnosed despite annual medical contact in the vast majority of patients.

When we compared the depression scores of our patients with the data from healthy cohorts in Germany, norm-based PCS and MCS scores of the overall population were close to 50 , whereas $27 \%$ of the study population showed MCS scores $<40$ and $12 \%$ had WHO-5 scores indicative of a clinically manifest depression. These observations confirm the results of several previously published international studies and support the need for regular psychological/psychiatric evaluation of cancer patients and cancer survivors $(13,52,53,54)$.

There are some limitations to our study. The size of the study group is limited and we restricted our analysis to three cancer entities. Moreover, our observations are derived from questionnaire-based voluntary selfdisclosures and not the actual medical records, which may distort our information on concurrent diseases and introduce inaccuracy regarding medical treatment. However, other health-care studies have shown that patients can provide valid (55) and reliable $(56,57,58)$ information about their treatment and diseases. Furthermore, the epidemiological cancer registry only collected data concerning first line therapy following initial diagnosis. It is therefore possible that some patients received additional treatment at relapse. At the time of the survey, none of the patients were receiving oncological therapy. The aim of this study was to assess the frequency of late effects after cancer therapy, defined as any disease occurring after therapy with a possible causal link to the specific treatment. As from our current data, a connection between a specific treatment and a particular late effect could not be derived. This matter remains an important subject for future studies. Additionally, we were forced to rely on historic data derived from independent population-based studies as an age-adjusted cohort was not available for comparative studies.

In summary, we were able to show that long-term cancer survivors with cancer treatment in adulthood are at a significantly elevated risk of developing endocrine and/or metabolic disorders such as hypo- or hyperthyroidism, osteoporosis as well as diabetes mellitus as has been reported for children and adolescents. Based on the incidence of NHL in Germany of $\sim 15 / 100000$ citizens per year and the combined disease related mortality, there are expected to be over 7000 patients every year newly considered long term NHL survivors (http://www.lymphome.de/InfoLymphome/NonHodgkin Lymphome/HaeufUrsache.jsp; http://www.tumorregistermuenchen.de/facts/surv/surv_C8285G.pdf). Even with regard to this rare entity, there are almost four times as many adult patients potentially suffering from late effects following NHL therapy than the overall annual incidence of cancer in childhood in Germany (http://www.kinderkrebsregister.de/) supporting the relevance of potential endocrine late effects in patients treated primarily in adulthood.

Routine oncological follow-up for most entities terminates 5 years after initial diagnosis when no signs of persistence or recurrence have emerged. Thereafter, most patients are referred to their GP for subsequent clinical follow-up. Our findings clearly show that a substantial subset of adult long-term cancer survivors can be expected to develop therapy-related late endocrine disorders, which due to their degree of complexity, will require interdisciplinary attention as it is already implemented following childhood cancer (59).

\section{Supplementary data}

This is linked to the online version of the paper at http://dx.doi.org/10.1530/ EJE-15-0174.

Declaration of interest

The authors declare that there is no conflict of interest that could be perceived as prejudicing the impartiality of the research reported.

\section{Funding}

This work was supported by an unrestricted grant from Pfizer Inc.

\section{References}

1 Berry DA, Cronin KA, Plevritis SK, Fryback DG, Clarke L, Zelen M, Mandelblatt JS, Yakovlev AY, Habbema JD \& Feuer EJ. Effect of screening and adjuvant therapy on mortality from breast cancer. New England Journal of Medicine 2005353 1784-1792. (doi:10.1056/ NEJMoa050518)

2 Armstrong GT, Pan Z, Ness KK, Srivastava D \& Robison LL. Temporal trends in cause-specific late mortality among 5-year survivors of childhood cancer. Journal of Clinical Oncology 201028 1224-1231. (doi:10.1200/JCO.2009.24.4608)

3 Ito Y, Miyashiro I, Ito H, Hosono S, Chihara D, Nakata-Yamada K, Nakayama M, Matsuzaka M, Hattori M, Sugiyama H et al. Long-term 
survival and conditional survival of cancer patients in Japan using population-based cancer registry data. Cancer Science 2014105 1480-1486. (doi:10.1111/cas.12525)

4 Elliott J, Fallows A, Staetsky L, Smith PW, Foster CL, Maher EJ \& Corner J. The health and well-being of cancer survivors in the UK: findings from a population-based survey. British Journal of Cancer 2011 105 (Suppl 1) S11-S20. (doi:10.1038/bjc.2011.418)

5 Khan NF, Mant D, Carpenter L, Forman D \& Rose PW. Long-term health outcomes in a British cohort of breast, colorectal and prostate cancer survivors: a database study. British Journal of Cancer 2011105 (Suppl 1) S29-S37. (doi:10.1038/bjc.2011.420)

6 Maddams J, Brewster D, Gavin A, Steward J, Elliott J, Utley M \& Moller H. Cancer prevalence in the United Kingdom: estimates for 2008. British Journal of Cancer 2009101 541-547. (doi:10.1038/sj.bjc. 6605148)

7 Smith GL, Smith BD, Giordano SH, Shih YC, Woodward WA, Strom EA, Perkins GH, Tereffe W, Yu TK \& Buchholz TA. Risk of hypothyroidism in older breast cancer patients treated with radiation. Cancer 2008112 1371-1379. (doi:10.1002/cncr.23307)

8 Treanor C, Santin O, Mills M \& Donnelly M. Cancer survivors with self-reported late effects: their health status, care needs and service utilisation. Psycho-oncology 201322 2428-2435. (doi:10.1002/ pon.3304)

9 Skolarus TA, Wolf AM, Erb NL, Brooks DD, Rivers BM, Underwood W III, Salner AL, Zelefsky MJ, Aragon-Ching JB, Slovin SF et al. American Cancer Society prostate cancer survivorship care guidelines. $C A$ : $A$ Cancer Journal for Clinicians 201464 225-249. (doi:10.3322/caac.21234)

10 Rowland JH \& Bellizzi KM. Cancer survivorship issues: life after treatment and implications for an aging population. Journal of Clinical Oncology 201432 2662-2668. (doi:10.1200/JCO.2014.55.8361)

11 Elston Lafata J, Simpkins J, Schultz L, Chase GA, Johnson CC, Yood MU, Lamerato L, Nathanson D \& Cooper G. Routine surveillance care after cancer treatment with curative intent. Medical Care 200543 592-599. (doi:10.1097/01.mlr.0000163656.62562.c4)

12 Snyder CF, Earle CC, Herbert RJ, Neville BA, Blackford AL \& Frick KD. Preventive care for colorectal cancer survivors: a 5-year longitudinal study. Journal of Clinical Oncology 200826 1073-1079. (doi:10.1200/ JCO.2007.11.9859)

13 Hudson MM, Mertens AC, Yasui Y, Hobbie W, Chen H, Gurney JG, Yeazel M, Recklitis CJ, Marina N, Robison LR et al. Health status of adult long-term survivors of childhood cancer: a report from the Childhood Cancer Survivor Study. Journal of the American Medical Association 2003 290 1583-1592. (doi:10.1001/jama.290.12.1583)

14 Chemaitilly W \& Sklar CA. Endocrine complications in long-term survivors of childhood cancers. Endocrine-Related Cancer 201017 R141-R159. (doi:10.1677/ERC-10-0002)

15 Brabant G, Toogood AA, Shalet SM, Frobisher C, Lancashire ER, Reulen RC, Winter DL \& Hawkins MM. Hypothyroidism following childhood cancer therapy - an under diagnosed complication. International Journal of Cancer. Journal International du Cancer 2012130 1145-1150. (doi:10.1002/ijc.26086)

16 van Dorp W, van Beek RD, Laven JS, Pieters R, de Muinck KeizerSchrama SM \& van den Heuvel-Eibrink MM. Long-term endocrine side effects of childhood Hodgkin's lymphoma treatment: a review. Human Reproduction Update 201218 12-28. (doi:10.1093/humupd/dmr038)

17 Gurney JG, Kadan-Lottick NS, Packer RJ, Neglia JP, Sklar CA, Punyko JA, Stovall M, Yasui Y, Nicholson HS, Wolden S et al. Endocrine and cardiovascular late effects among adult survivors of childhood brain tumors: Childhood Cancer Survivor Study. Cancer 200397 663-673. (doi:10.1002/cncr.11095)

18 Schmiegelow M, Lassen S, Poulsen HS, Feldt-Rasmussen U, Schmiegelow K, Hertz H \& Muller J. Cranial radiotherapy of childhood brain tumours: growth hormone deficiency and its relation to the biological effective dose of irradiation in a large population based study. Clinical Endocrinology 200053 191-197. (doi:10.1046/j.1365-2265. 2000.01079.x)
19 Darzy KH \& Shalet SM. Hypopituitarism as a consequence of brain tumours and radiotherapy. Pituitary 20058 203-211. (doi:10.1007/ s11102-006-6042-4)

20 Brazier JE, Harper R, Jones NM, O'Cathain A, Thomas KJ, Usherwood T \& Westlake L. Validating the SF-36 health survey questionnaire: new outcome measure for primary care. BMJ 1992305 160-164. (doi:10.1136/bmj.305.6846.160)

21 Morfeld M, Kirchberger I \& Bullinger M. SF-36 Fragebogen zum Gesundheitszustand. Göttingen: Hogrefe, 2011.

22 Bonsignore M, Barkow K, Jessen F \& Heun R. Validity of the five-item WHO Well-Being Index (WHO-5) in an elderly population. European Archives of Psychiatry and Clinical Neuroscience 2001251 (Suppl 2) II27-II31.

23 Meisinger C, Ittermann T, Wallaschofski H, Heier M, Below H, Kramer A, Doring A, Nauck M \& Volzke H. Geographic variations in the frequency of thyroid disorders and thyroid peroxidase antibodies in persons without former thyroid disease within Germany. European Journal of Endocrinology 2012167 363-371. (doi:10.1530/EJE-12-0111)

24 Fuchs J, Rabenberg M \& Scheidt-Nave C. Prevalence of selected musculoskeletal conditions in Germany: results of the German Health Interview and Examination Survey for Adults (DEGS1). Bundesgesundheitsblatt, Gesundheitsforschung, Gesundheitsschutz 201356 678-686. (doi:10.1007/s00103-013-1687-4)

25 Heidemann C, Du Y, Schubert I, Rathmann W \& Scheidt-Nave C. Prevalence and temporal trend of known diabetes mellitus: results of the German Health Interview and Examination Survey for Adults (DEGS1). Bundesgesundheitsblatt, Gesundheitsforschung, Gesundheitsschutz 201356 668-677. (doi:10.1007/s00103-012-1662-5)

26 Knopf H \& Grams D. Medication use of adults in Germany: results of the German Health Interview and Examination Survey for Adults (DEGS1). Bundesgesundheitsblatt, Gesundheitsforschung, Gesundheitsschutz 201356 868-877. (doi:10.1007/s00103-013-1667-8)

27 Gawade PL, Hudson MM, Kaste SC, Neglia JP, Wasilewski-Masker K, Constine LS, Robison LL \& Ness KK. A systematic review of selected musculoskeletal late effects in survivors of childhood cancer. Current Pediatric Reviews 201410 249-262. (doi:10.2174/157340051066614 1114223827)

28 den Hoed MA, Klap BC, Te Winkel ML, Pieters R, van Waas M, Neggers SJ, Boot AM, Blijdorp K, van Dorp W, Pluijm SM et al. Bone mineral density after childhood cancer in 346 long-term adult survivors of childhood cancer. Osteoporosis International 201526 521-529. (doi:10.1007/s00198-014-2878-z)

29 Cabanillas ME, Lu H, Fang S \& Du XL. Elderly patients with nonHodgkin lymphoma who receive chemotherapy are at higher risk for osteoporosis and fractures. Leukemia \& Lymphoma 200748 1514-1521. (doi:10.1080/10428190701471973)

30 Majhail NS, Ness KK, Burns LJ, Sun CL, Carter A, Francisco L, Forman SJ, Bhatia S \& Baker KS. Late effects in survivors of Hodgkin and nonHodgkin lymphoma treated with autologous hematopoietic cell transplantation: a report from the bone marrow transplant survivor study. Biology of Blood and Marrow Transplantation 200713 1153-1159. (doi:10.1016/j.bbmt.2007.06.003)

31 Holmqvist AS, Olsen JH, Andersen KK, Licht Sde F, Hjorth L, Garwicz S, Moell C, Anderson H, Wesenberg F, Tryggvadottir L et al. Adult life after childhood cancer in Scandinavia: diabetes mellitus following treatment for cancer in childhood. European Journal of Cancer 201450 1169-1175. (doi:10.1016/j.ejca.2014.01.014)

32 Neville KA, Cohn RJ, Steinbeck KS, Johnston K \& Walker JL. Hyperinsulinemia, impaired glucose tolerance, and diabetes mellitus in survivors of childhood cancer: prevalence and risk factors. Journal of Clinical Endocrinology and Metabolism 200691 4401-4407. (doi:10.1210/ jc.2006-0128)

33 Meacham LR, Sklar CA, Li S, Liu Q, Gimpel N, Yasui Y, Whitton JA, Stovall M, Robison LL \& Oeffinger KC. Diabetes mellitus in long-term survivors of childhood cancer. Increased risk associated with radiation therapy: a report for the childhood cancer survivor study. Archives of 
Internal Medicine 2009169 1381-1388. (doi:10.1001/archinternmed. 2009.209)

34 de Vathaire F, El-Fayech C, Ben Ayed FF, Haddy N, Guibout C, Winter D, Thomas-Teinturier C, Veres C, Jackson A, Pacquement H et al. Radiation dose to the pancreas and risk of diabetes mellitus in childhood cancer survivors: a retrospective cohort study. Lancet. Oncology 201213 1002-1010. (doi:10.1016/S1470-2045(12)70323-6)

35 Madanat LM, Lahteenmaki PM, Hurme S, Dyba T, Salmi TT \& Sankila R. Hypothyroidism among pediatric cancer patients: a nationwide, registry-based study. International Journal of Cancer. Journal International du Cancer 2008122 1868-1872. (doi:10.1002/ijc.23277)

36 Chow EJ, Friedman DL, Stovall M, Yasui Y, Whitton JA, Robison LL \& Sklar CA. Risk of thyroid dysfunction and subsequent thyroid cancer among survivors of acute lymphoblastic leukemia: a report from the Childhood Cancer Survivor Study. Pediatric Blood \& Cancer 200953 432-437. (doi:10.1002/pbc.22082)

37 Sklar C, Whitton J, Mertens A, Stovall M, Green D, Marina N, Greffe B, Wolden $\mathrm{S} \&$ Robison L. Abnormalities of the thyroid in survivors of Hodgkin's disease: data from the Childhood Cancer Survivor Study. Journal of Clinical Endocrinology and Metabolism 200085 3227-3232.

38 Veiga LH, Lubin JH, Anderson H, de Vathaire F, Tucker M, Bhatti P, Schneider A, Johansson R, Inskip P, Kleinerman R et al. A pooled analysis of thyroid cancer incidence following radiotherapy for childhood cancer. Radiation Research 2012178 365-376. (doi:10.1667/ RR2889.1)

39 Rosen RC, Fisher WA, Eardley I, Niederberger C, Nadel A \& Sand M. The multinational Men's Attitudes to Life Events and Sexuality (MALES) study: I. Prevalence of erectile dysfunction and related health concerns in the general population. Current Medical Research and Opinion 200420 607-617. (doi:10.1185/030079904125003467)

40 Brydoy M, Fossa SD, Dahl O \& Bjoro T. Gonadal dysfunction and fertility problems in cancer survivors. Acta Oncologica 200746 480-489. (doi:10.1080/02841860601166958)

41 DeSimone M, Spriggs E, Gass JS, Carson SA, Krychman ML \& Dizon DS. Sexual dysfunction in female cancer survivors. American Journal of Clinical Oncology 201437 101-106. (doi:10.1097/COC.0b013e3182 $48 \mathrm{~d} 89 \mathrm{~d})$

42 Constine LS, Rubin P, Woolf PD, Doane K \& Lush CM. Hyperprolactinemia and hypothyroidism following cytotoxic therapy for central nervous system malignancies. Journal of Clinical Oncology 19875 1841-1851.

43 Green DM, Kawashima T, Stovall M, Leisenring W, Sklar CA, Mertens AC, Donaldson SS, Byrne J \& Robison LL. Fertility of male survivors of childhood cancer: a report from the Childhood Cancer Survivor Study. Journal of Clinical Oncology 201028 332-339. (doi:10.1200/JCO.2009.24.9037)

44 Sklar CA, Mertens AC, Mitby P, Whitton J, Stovall M, Kasper C, Mulder J, Green D, Nicholson HS, Yasui Y et al. Premature menopause in survivors of childhood cancer: a report from the childhood cancer survivor study. Journal of the National Cancer Institute 200698 890-896. (doi:10.1093/jnci/dji243)

45 Sklar CA \& Constine LS. Chronic neuroendocrinological sequelae of radiation therapy. International Journal of Radiation Oncology, Biology, Physics 199531 1113-1121. (doi:10.1016/0360-3016(94)00427-M)
46 Clayton PE \& Shalet SM. Dose dependency of time of onset of radiationinduced growth hormone deficiency. Journal of Pediatrics 1991118 226-228. (doi:10.1016/S0022-3476(05)80487-1)

47 Darzy KH. Radiation-induced hypopituitarism after cancer therapy: who, how and when to test. Nature Clinical Practice. Endocrinology \& Metabolism 20095 88-99. (doi:10.1038/ncpendmet1051)

48 Pachman DR, Barton DL, Swetz KM \& Loprinzi CL. Troublesome symptoms in cancer survivors: fatigue, insomnia, neuropathy, and pain. Journal of Clinical Oncology 201230 3687-3696. (doi:10.1200/JCO. 2012.41.7238)

49 Clanton NR, Klosky JL, Li C, Jain N, Srivastava DK, Mulrooney D, Zeltzer L, Stovall M, Robison LL \& Krull KR. Fatigue, vitality, sleep, and neurocognitive functioning in adult survivors of childhood cancer: a report from the Childhood Cancer Survivor Study. Cancer 2011117 2559-2568. (doi:10.1002/cncr.25797)

50 Suh E, Daugherty CK, Wroblewski K, Lee H, Kigin ML, Rasinski KA, Ford JS, Tonorezos ES, Nathan PC, Oeffinger KC et al. General internists' preferences and knowledge about the care of adult survivors of childhood cancer: a cross-sectional survey. Annals of Internal Medicine 2014160 11-17. (doi:10.7326/M13-1941)

51 Khan NF, Evans J \& Rose PW. A qualitative study of unmet needs and interactions with primary care among cancer survivors. British Journal of Cancer 2011105 (Suppl 1) S46-S51. (doi:10.1038/bjc.2011.422)

52 Zebrack BJ, Zeltzer LK, Whitton J, Mertens AC, Odom L, Berkow R \& Robison LL. Psychological outcomes in long-term survivors of childhood leukemia, Hodgkin's disease, and non-Hodgkin's lymphoma: a report from the Childhood Cancer Survivor Study. Pediatrics 2002110 42-52. (doi:10.1542/peds.110.1.42)

53 Muzzatti B, Flaiban C, Surbone A \& Annunziata MA. Quality of life profile in Italian long-term cancer survivors. Quality of Life Research 201524 959-967. (doi:10.1007/s11136-014-0831-4)

54 Zeltzer LK, Recklitis C, Buchbinder D, Zebrack B, Casillas J, Tsao JC, Lu Q \& Krull K. Psychological status in childhood cancer survivors: a report from the Childhood Cancer Survivor Study. Journal of Clinical Oncology 200927 2396-2404. (doi:10.1200/JCO.2008.21.1433)

55 Ritterhoff N. Wie gut kennen Patienten ihre Krankheit und Behandlung? Ein Vergleich von Patientenangaben, Arztangaben und Registerdaten in der onkologischen Versorgung. Medizinische Fakultät Institut für Krebsepidemiologie e.V. Universität zu Lübeck, 2010.

56 Waldmann A, Dreckschmidt J, Pritzkuleit R \& Katalinic A. Test-retest reliability of the OVIS Questionnaire - an instrument to evaluate oncological care from a patient's point of view. Gesundheitswesen 2010 72 707-713. (doi:10.1055/s-0029-1242787)

57 Slanger T, Mutschelknauss E, Kropp S, Braendle W, Flesch-Janys D \& Chang-Claude J. Test-retest reliability of self-reported reproductive and lifestyle data in the context of a German case-control study on breast cancer and postmenopausal hormone therapy. Annals of Epidemiology 200717 993-998. (doi:10.1016/j.annepidem.2007.07.094)

58 Adelstein BA, Irwig L, Macaskill P, Katelaris PH, Jones DB \& Bokey L. A self administered reliable questionnaire to assess lower bowel symptoms. BMC Gastroenterology 2008 8 8. (doi:10.1186/1471-230X-8-8)

59 Richards M, Corner J \& Maher J. The National Cancer Survivorship Initiative: new and emerging evidence on the ongoing needs of cancer survivors. British Journal of Cancer 20111 S1-S4. (doi:10.1038/ bjc.2011.416)

Received 12 February 2015

Revised version received 27 April 2015

Accepted 5 May 2015 